\title{
In-Situ SEM Observation of Deformation and Fracture Process in Plasma-Sprayed CoNiCrAlY Thin Film*
}

\author{
Masayuki ARAI** \\ ${ }^{* *}$ Materials Science Research Lab., Central Research Institute of Electric Power Industry, \\ 2-11-1 Iwado-kita, Komae-shi, Tokyo 201-8511, Japan \\ E-mail: marai@criepi.denken.or.jp
}

\begin{abstract}
In this study, we examine those properties of freestanding CoNiCrAlY thin film detached chemically from the coated substrate. Tensile tests are conducted using the small testing device, which was developed by us, inserted into a vacuum chamber of a scanning electron microscope (SEM). Based on SEM continuous observation during tensile loading of the thin film, the deformation and fracture mechanisms of freestanding CoNiCrAlY are discussed. It was found that CoNiCrAlY thin film has a typical brittle-ductile transition; it indicates brittle deformation and fracture at testing temperature lower than $700[\mathrm{~K}]$. In the testing temperature higher than that, the CoNiCrAlY thin film elongates and is fractured with a high ductility. The reason for this transition was considered from SEM observations to be brought by mobility such as splat boundary sliding occurred during tensile loading. SEM also showed that a large inelastic deformation observed at the high-temperature is caused by the damage factors of both the micro cracking formed at splat boundary and the crack opening. Those factors leads to ductile fracture in CoNiCrAlY thin film exposed at the high temperature.
\end{abstract}

Key words: Thermal Barrier Coating, Plasma Spraying, Mechanical Properties, CoNiCrAlY, Thin Film, In-Situ Observation, SEM

\section{Introduction}

Thermal barrier coatings (TBCs) are deposited on the surface of high-temperature components in gas turbines (GTs) in order to prevent those components from high temperature gas combustion. TBC deposition is usually conducted with plasma spray technique, and has dual-layer structure composed of bond coating and top coating layers. Top coating layer is barrier layer against a high-temperature environment. Bond coating layer has a role of an improvement for high-temperature oxidation in Ni-based or Co-based superalloy components and cohesion of top coating layer. However, thermal stress caused by thermal expansion mismatch between top coating layer and substrate via bond coating leads to serious damages such as TBC cracking and spallation during in-service of GTs.

Bond coating layer, especially employed in TBCs, is composed of MCrAlY alloy $(\mathrm{M}=\mathrm{Co}, \mathrm{Ni}, \mathrm{CoNi}$ and $\mathrm{NiCo})$, and typical thickness is very thin as $100 \mu \mathrm{m}$ in comparison with top coating of $500 \mu \mathrm{m}$ thickness. It is known [1] that the exposed temperature affects the following fracture feature in bond coating; the bond coating deforms with low ductility when exposed at the lower temperature. In the temperature higher than that, that bond coating property indicates very high ductility such as several ten percent for fracture strain. Thus, this mechanical response such as brittle-ductile transition in dependence of the exposed temperature condition is known to bring about the bond coat originated damages as 
following examples. In GT blade components, out-of-phase type thermo-mechanical loading is cyclically subjected according to start-stop operation of GT [2]. An important factor in this type complex loading is to induce tensile loading at a lower temperature in the out-of-phase load-temperature pattern, because it could lead to brittle cracking in bond coating layer. In the other example, it is recognized that the metal temperature in the blade, which is kept at a constant during steady operation in GT, affect coating stress in top coating layer. That is, this high temperature during GT steady operation brings elongation of bond coating layer, and could form stress relaxation in top coating layer [3].

A lot of efforts for measuring the mechanical property in bond coatings have been done. Now, we can see some data of MCrAlY into the reference [1]. However, it should be noticed that the specimen geometry employed for those tests is a standard tensile test specimen shape such as millimeter size in spite of bond coating deposition thickness in micrometer in GT components. Recently, the alternated technique has been developed for measuring micrometer-size properties in bond coating layer. The techniques were given by indentation test [4] and small punch test [5]. As is well known, indentation test is method to evaluate stress-strain curve via indentation load versus displacement. Indentation displacement of tip indented into the bond coating could be affected by deformation constraint from stiff substrate. This constraint effect brings somewhat error in stress-strain curve obtained by the indentation test. Small punch test is method indenting cylindrical punch with flat bottom edge on the coated sample, and bending the overall coated specimen. The measurement results, which are obtained as punch load versus indentation displacement curve, allow us only relative evaluation for deformation resistance of the sample.

In this study, the bond coating thin film detached chemically from the coated sample is employed in order to examine about tensile properties under various temperature conditions. Tensile test is conducted using small-size tensile testing device, which can insert into the vacuum chamber of a scanning microscope (SEM). This device developed by our group [6], [7], [8] can do tensile test by miniature DC motor, and fatigue test by piezoelectric-ceramic actuator under a high-temperature condition (up to maximum temperature $1273[\mathrm{~K}]$, however maximum temperature depends on the intrinsic electric resistance of the sample) by flowing direct current into the sample. However the special testing device has various function for tests, this report is limited to the results of stress stain curve, yield stress and fracture strain for CoNiCrAlY thin film, which has the same chemical composition of the bond coating applied to typical GT blade surface. The associated deformation and fracture mechanisms of the CoNiCrAlY thin film are discussed via in-situ observation during a high-temperature testing, and also fracture surface of the specimen after finishing the tensile tests by SEM.

\section{Experiment}

\subsection{CoNiCrAIY thin film preparation}

Specimens were fabricated using an atmospheric plasma spraying process. The powder employed for CoNiCrAlY deposition is AMDRY 9954 (Sulzer Metco) and the chemical composition indicates in Table 1. The substrate was aluminum alloy plate. After polishing the surface of the substrate, the surface was grid-blasted (WA \#60). CoNiCrAlY was deposited using M-1000+F4 gun $(38 \mathrm{~kW})$ under a mixture gas of $\mathrm{Ar}$ and $\mathrm{H}_{2}$ up to the deposition thickness $200 \mu \mathrm{m}$.

The specimen geometry used in this study is shown in Fig.1. The specimen was cut mechanically with wire cutter from CoNiCrAlY coated plate-shape substrate. After this process, CoNiCrAlY thin film specimen was detached from substrate with a chemical treatment. This detached thin film specimen was polished up to $100 \mu \mathrm{m}$ thickness. 
Table1 Chemical composition of CoNiCrAlY employed in this study (wt\%)

\begin{tabular}{cccccccccccc}
\hline $\mathrm{Al}$ & $\mathrm{C}$ & $\mathrm{Co}$ & $\mathrm{Cr}$ & $\mathrm{Fe}$ & $\mathrm{Ni}$ & $\mathrm{P}$ & $\mathrm{S}$ & $\mathrm{Se}$ & $\mathrm{Y}$ & $\mathrm{O}_{2}$ & $\mathrm{~N}_{2}$ \\
\hline 7.73 & 0.01 & 38.9 & 20.7 & 0.03 & 31.9 & 0.01 & 0.01 & 0.01 & 0.45 & 0.02 & 0.007 \\
\hline
\end{tabular}

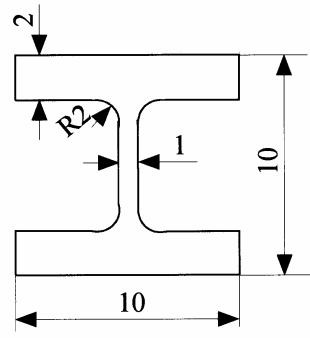

Fig.1 Specimen geometry of CoNiCrAlY thin film (dimensions in mm)

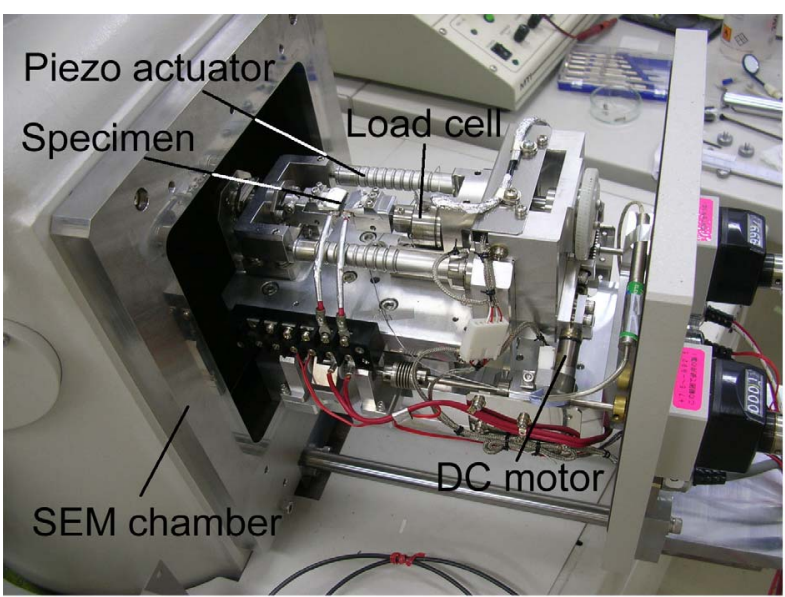

(a) High-temperature small-size testing device

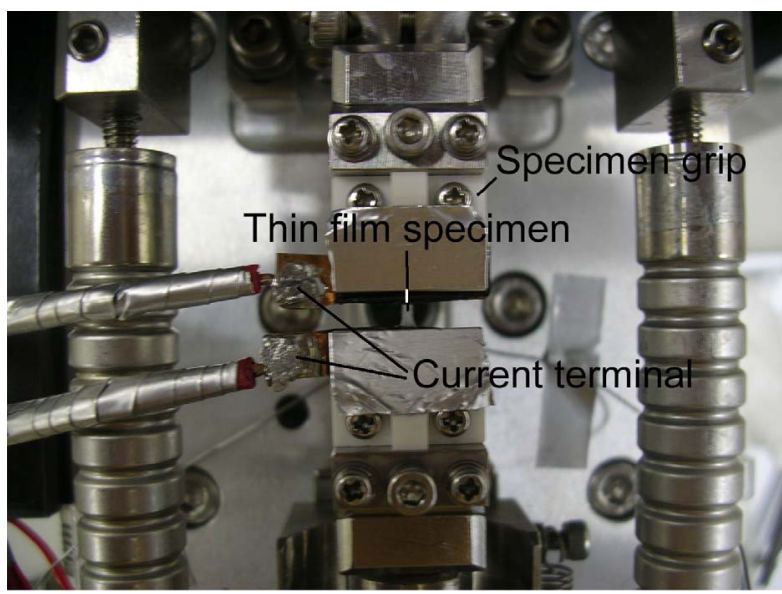

(b) Appearance of thin film specimen fixed with grips in the testing device

Fig. 2 Photograph of small testing device combined with FE-SEM. This device can do tensile test using miniature DC motor and fatigue test using piezoelectric ceramic actuator under a high-temperature

\subsection{Test technique and test procedure}

In-situ high-temperature small size testing device combined with a scanning electron microscope (SEM), which was developed by our group, is shown in Fig.2 (a) and (b). Fig.3 indicates the associated system diagram for controlling tests. The tensile and compressive 
loads can be imposed for the specimen via a multi-layered piezoelectric actuator (Five layered ceramic type actuator manufactured by TOKIN: maximum displacement $68[\mu \mathrm{m}]$ and generated load $800[\mathrm{~N}]$ ), which is powered by a power amp. (Piezoelectric Driver manufacture by MESS-TEK: input signal for controlling 0-5[V] and output voltage $0-150[\mathrm{~V}])$. In this device, miniature DC motor is also available instead of the piezoelectric actuator, when needing more large displacement for carrying out a tensile test. An applied load is measured by a load cell (LUR-A-100N, KYOWA, load capacity $100[\mathrm{~N}]$ ). Loading pattern such as monotonic tensile and trapezoidal modes can be generated with the servo controller (Controller 4826, shimadzu) specially modified for this study. A signal from the servo controller via load cell is transmitted to a power amp for adjusting automatically a suitable loading pattern. Thin film specimen is heated by flowing directly an electric current in the specimen. The specimen temperature is measured by a pyrometer (IGA, LEC: spot size $\phi 0.2[\mathrm{~mm}])$ during tests and controlled using the temperature controller that was developed by us. This temperature controller is consisted of small-power supplier $(12 \mathrm{~V}$, 0-5A) and signal controller (KP1000, CHINO). Voltage signals from load cell, displacement measured by an encorder and the specimen temperature are stored continuously in a personal computer.

In this study, tensile tests are conducted under various temperature conditions (293, 673,1013 and $1073[\mathrm{~K}]$ ) in order to obtain stress-strain curve of CoNiCrAlY thin film. Here, the strain was defined by dividing the displacement measured by encorder by an initial distance between specimen grips.

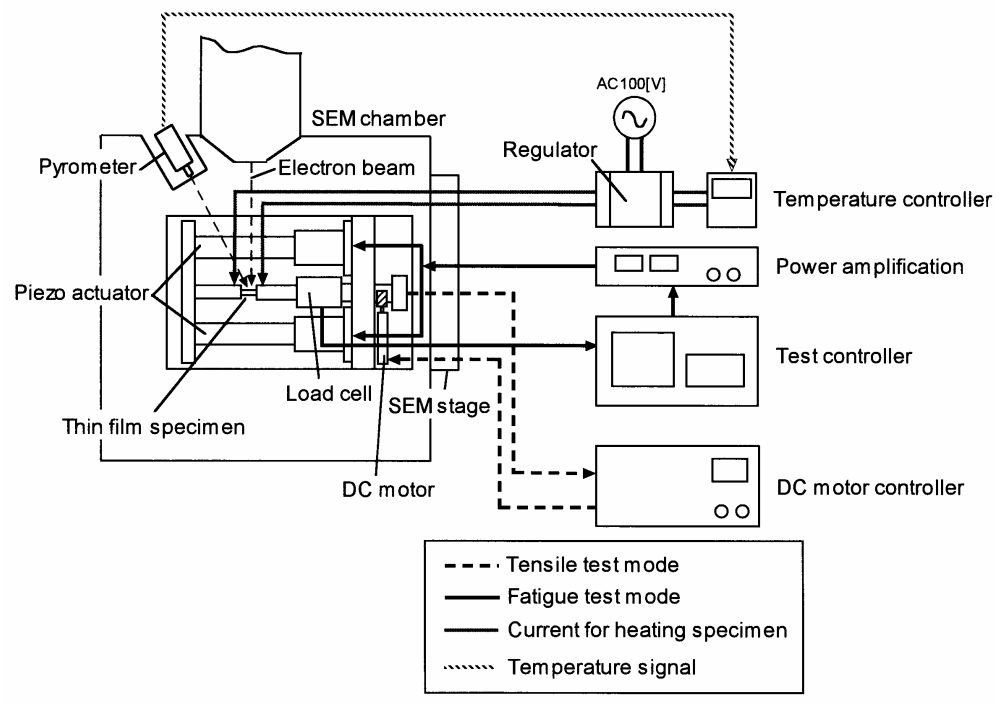

Fig.3 System diagram for controlling tests

\section{Results}

\subsection{High-temperature test}

Fig.4 indicates a typical stress-strain curve obtained at testing temperatures 293, 573, 1013 and $1073[\mathrm{~K}]$. Stress increases linearly with increase of strain under all temperature condition. It was also found that tensile strength decreases with increasing test temperature and fracture strain increases. Previous research [1] has shown that tensile strength of CoNiCrAlY sample has approximately $1000 \mathrm{MPa}$ at room temperature, and its value is ten-times higher than one obtained by us. It should notice that the previous data [1] has been 
obtained using millimeter size standard specimen that was fabricated by the vacuum plasma spraying process. The fabrication of coating with thick thickness could give a complex heat history in a microstructure in the bond coating in comparison of thinner thickness case employed in GT components. Thus, it is considered that such fabrication process affects the stress-strain curve.

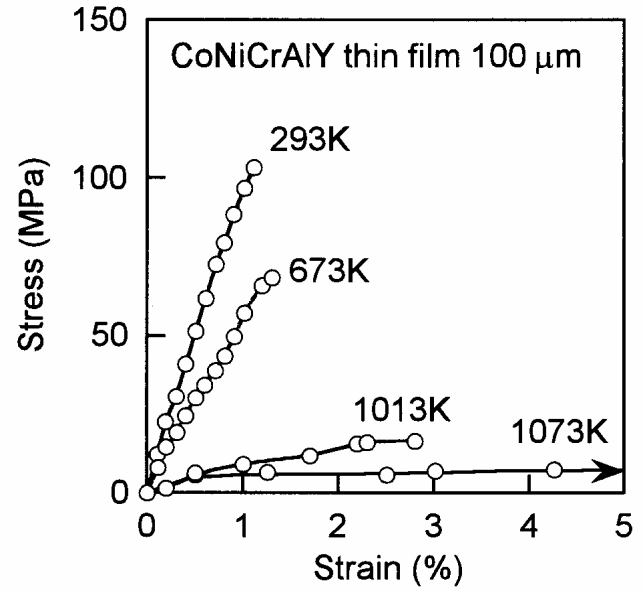

Fig.4 Stress-strain curve of CoNiCrAlY thin film

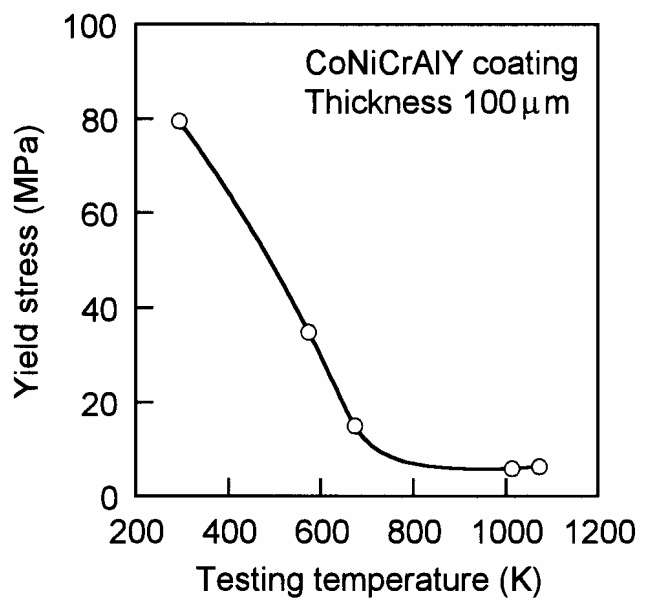

Fig.5 Relationship between yield stress and testing temperature

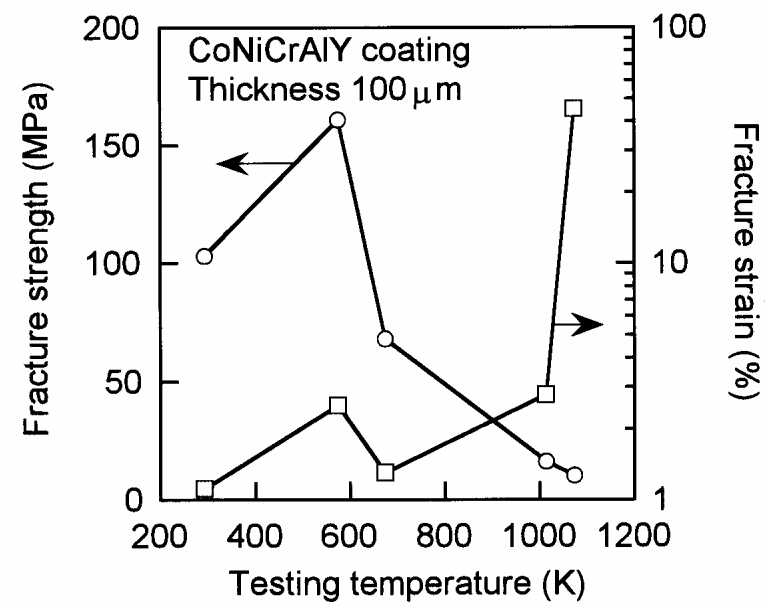

Fig.6 Variation of fracture strength and fracture strain against testing temperature 
Fig.5 indicates relationship between yield stress and testing temperature. The yield stress of $80 \mathrm{MPa}$ at room temperature decreases with increasing test temperature up to reaching to $700[\mathrm{~K}]$. This trend is quite similar to the previous work [1].

Fig. 6 indicates relation of tensile strength and fracture strain for all testing temperature conditions. Tensile strength decreases with increase of testing temperature, however fracture strain increases with the temperature as recommended in Fig.4. The fracture strain at maximum temperature condition takes $60[\%]$. This results claims that CoNiCrAlY thin film has an obvious brittle-ductile transition as same as the previous work [1].

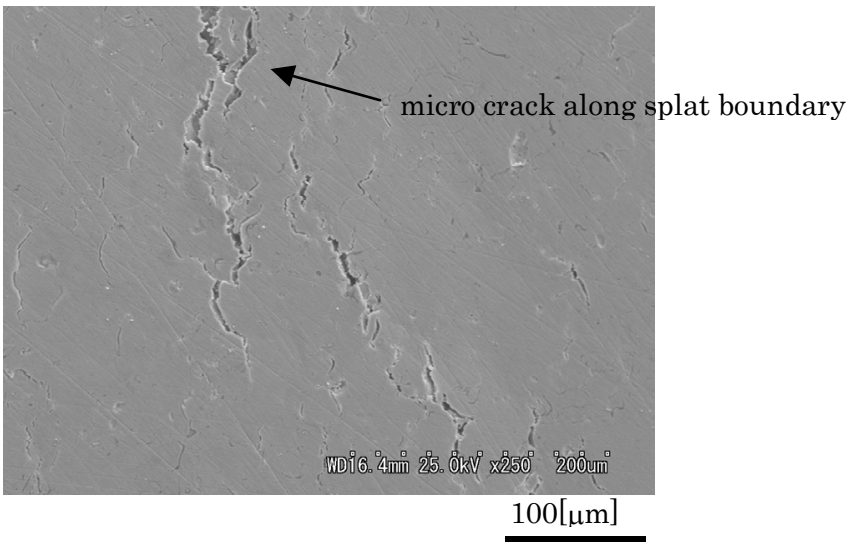

(a) Strain $=1.4 \%$

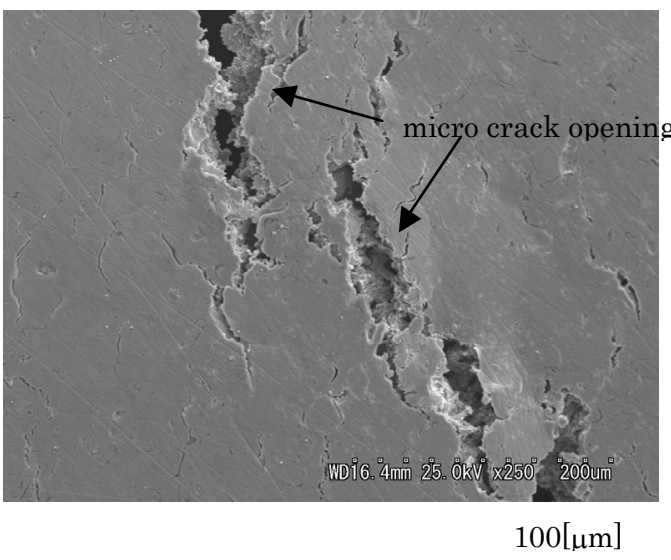

(b) Strain $=2.0 \%$

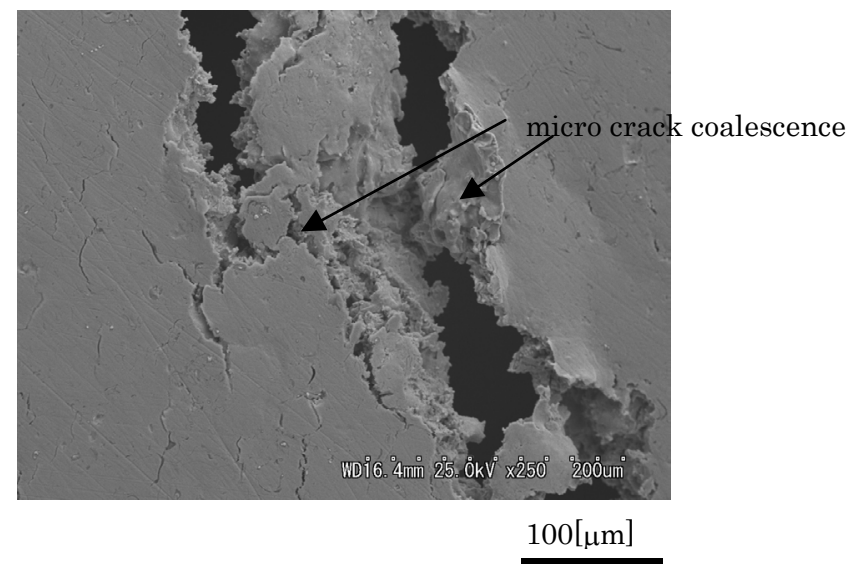

(c) Strain $=2.5 \%$

Fig.7 Continuous observation results using CoNiCrAlY tensile test at 1013K in SEM 


\subsection{In-situ SEM observation results}

Fig.7 shows SEM pictures observed during tensile test at 1013[K]. This condition corresponds to lowest yield stress, that is, highest fracture strain in comparison with the other testing temperature condition. This continuous observation reveals that a lot of micro cracks initiate at everywhere splat boundaries normal to loading direction at strain $1.4 \%$. Reaching to strain $2.0 \%$, those micro cracks open and some cracks propagate along the splat boundary. Increase of strain leads to larger crack opening and coalescence of cracks together with near-cracks, which fracture was occurred, consequently. This SEM observation results claims that higher exposure temperature brings splat boundary fracture during tensile loading.

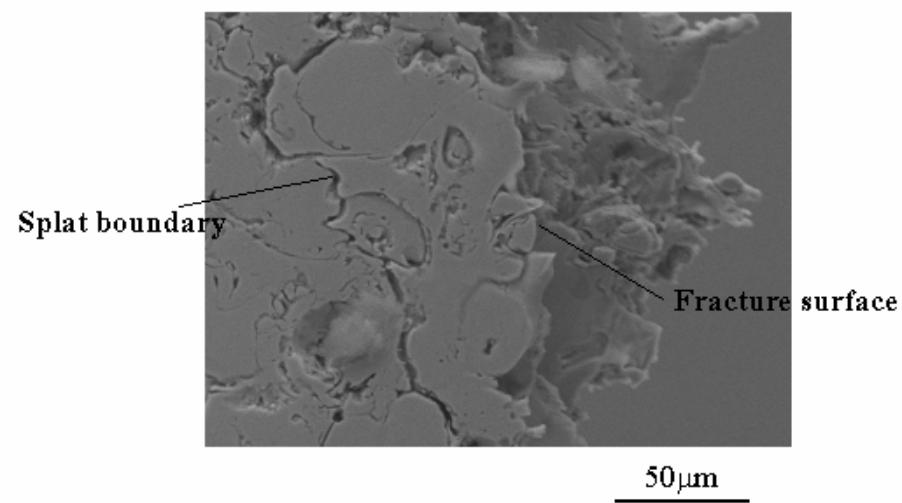

(a) Room temperature (293K)

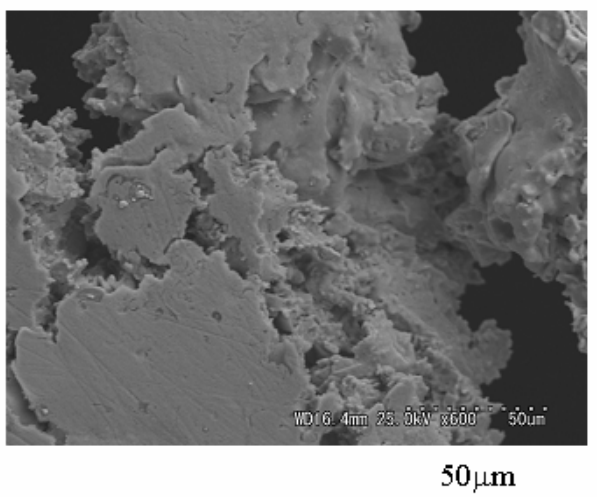

(b) $1013 \mathrm{~K}$

Fig. 8 Specimen surface observation around fracture parts by SEM

Fig.8 indicates SEM observation around fracture part of specimen surface after finishing tensile test. Figure involves testing temperature condition: 293 and 1073[K]. Those pictures reveals that fracture feature in $273[\mathrm{~K}]$ is inner-splat fracture, that is, crack propagates into splats. Micro cracks at the splat boundaries as observed in 1073[K] were not observed on the specimen surface in $273[\mathrm{~K}]$. The higher temperature fracture feature at $1073[\mathrm{~K}]$, of course, indicates splat boundary fracture.

Fig.9 indicates fracture surface observation after finishing tensile tests by SEM. In case 293 [K], a lamella-type deposited splat structure is obviously observed. Brittle fracture feature in lower test temperature from this picture provides that crack propagated straightly into the splats. On the other hand, in case of $1973[\mathrm{~K}]$, smooth round surface of splat is seen in the picture, which indicates splat boundary surface. 


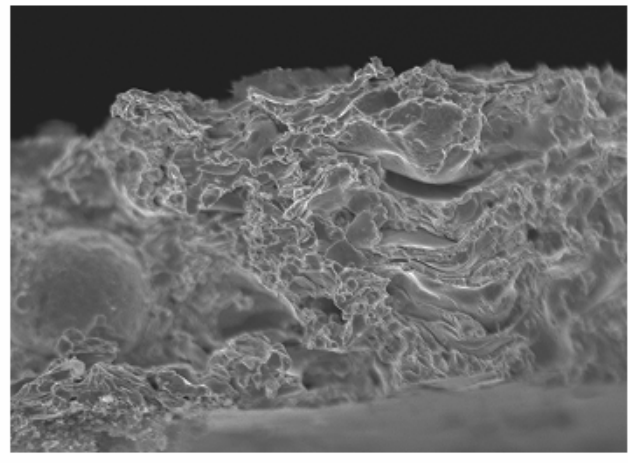

$20 \mu \mathrm{m}$

(a) Room temperature (293K)

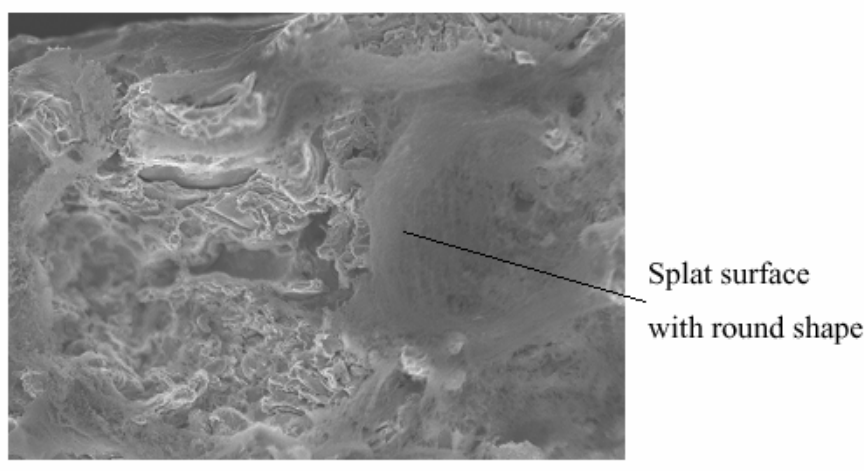

$20 \mu \mathrm{m}$

(b) $1013 \mathrm{~K}$

Fig.9 Fracture surface feature after finishing the tensile testing

Tensile test results and associated SEM observations can be summarized following:

(1) Yield stress and fracture strength in testing temperature lower than $700[\mathrm{~K}]$ has higher values. On the other hand, those property for temperature condition higher than $700[\mathrm{~K}]$ has low yield stress and fracture strength, however CoNiCrAlY thin film has very high ductility such as fifty percent.

(2) Testing temperature also affects strongly fracture feature. That is, the crack propagates with straight path into splats, and the specimen is finally broken with brittle feature in lower testing temperature. In higher testing temperature, a lot of micro cracks initiate at the splat boundaries and open such as opening mouth. Consequentially, coalescence of micro cracks along splat boundary leads to fracture.

\section{Discussion}

Influence of the exposed temperature on Vickers hardness in CoNiCrAlY is shown in Fig.10. This result was obtained using CoNiCrAlY sample exposed by an electric furnace. It was found that the hardness of CoNiCrAlY takes constant value with independent of the exposed temperature. It was considered that the exposed temperature does not affect mechanical properties of splat itself characterized microstructure of CoNiCrAlY fabricated with plasma spray technique. This result emphasizes an importance of splat boundary behavior in the deformation process of CoNiCrAlY. That is, the splat boundary sliding deformation has to be involved as one in deformation mechanisms under smaller loading of CoNiCrAlY thin film as same as claimed in zirconia coating by Thompson and Clyne [9], in order to explain inelastic deformation appeared in higher testing temperature condition. 
Also, the crack opening would be contributed as main deformation mechanism in larger loading.

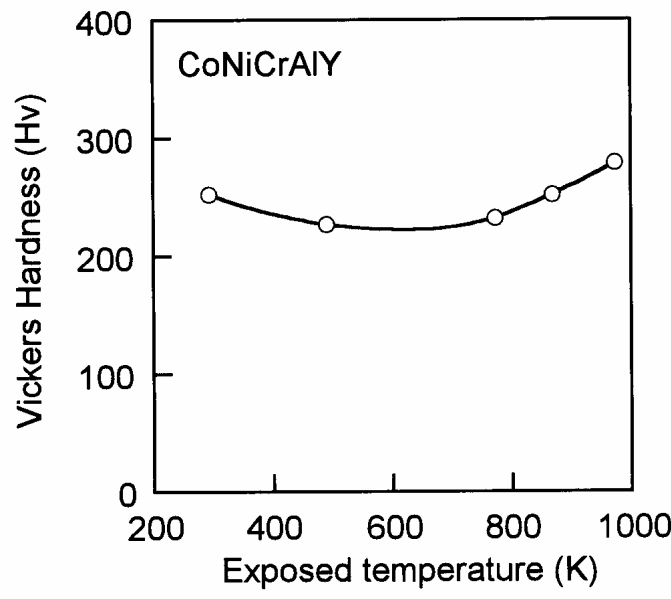

Fig.10 Relationship between Vickers hardness and exposed temperature.

Following deformation and fracture mechanism is considered based on the experimental results of tensile tests and SEM observation. Fig.11 illustrates to give explanation of deformation and fracture mechanisms of CoNiCrAlY. In the exposed temperature lower than brittle-ductile transition point, cohesion at splat boundary between splats has strong. Thus, CoNiCrAlY thin film deformed with elastic distortion in the splat, and finally fractured with crack propagation into splat, which brittle fracture caused. Here, we call this mode "inner-splat fracture type". On the other hand, in the exposed temperature higher than the transition point, the splat boundary cohesion becomes soft and thus splat boundary sliding is easily occurred during tensile loading. Increase of tensile loading leads to micro crack initiation at splat boundary and its opening. The crack opening contributes inelastic deformation in addition of splat boundary sliding. Consequentially, micro cracks coalesce together and fracture was occurred. We call this mode "splat boundary fracture type". It was found that fracture feature can divide into two types at brittle-ductile transition point.
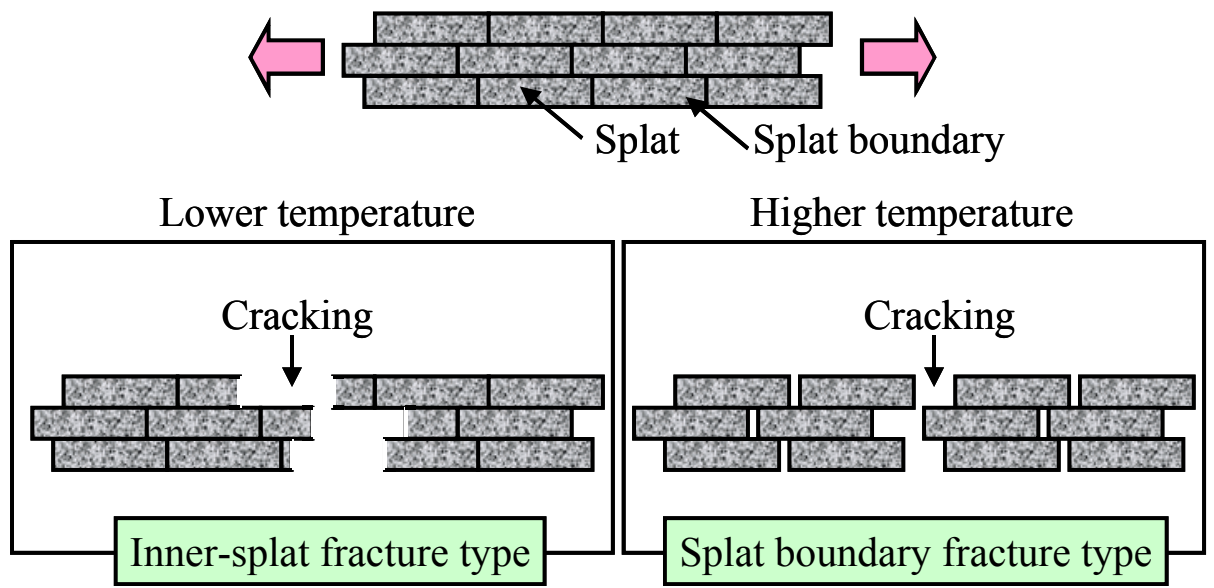

Fig.11 Schematic illustration of deformation and fracture mechanisms of CoNiCrAlY

\section{Conclusion}

In this report, tensile tests were conducted using CoNiCrAlY thin film detached 
chemically from the coated substrate, and in-situ SEM observation was done for examining deformation and fracture process in the thin film. The obtained results are following;

(1) CoNiCrAlY thin film indicated that yield stress and fracture strength has very high in testing temperature lower than $700[\mathrm{~K}]$, and associated fracture strain is very poor. On the other hand, testing temperature higher than $700[\mathrm{~K}]$ gave low yield stress and fracture strength for CoNiCrAlY thin film, but became high fracture strength as fifty percent.

(2) It was found that fracture feature was different as following two types; i) inner-splat fracture type which crack propagates into the splat, and ii) splat-boundary fracture type which crack propagates along the splat boundary and opens as mouth opening. Those features are obviously distinguished via brittle-ductile transition temperature $700[\mathrm{~K}]$.

It was considered from SEM observation that high ductility in higher testing temperature condition was caused by splat boundary sliding and crack opening. Lower ductility, that is, brittle was brought by stronger cohesion of splat boundary. Thus, crack propagated inside the splat.

\section{References}

(1) Tamarin, Y., Protective Coatings for Turbine Blades, ASM International (2002) 97-160.

(2) Johnson, P.K., Arana, M., Ostolaza, K.M. Bressers, J., Crack initiation in a coated and an uncoated nickel-base superalloy under TMF conditions, Journal of Engineering for Gas Turbines and Power Vol. 120 (1998), pp.792-795.

(3) Arai, M., Sakuma, T., Iwata, U., Saitoh, M., Proposal of delamination life prediction method of thermal barrier coating layer under thermal cycle condition, Journal of the Society of Materials Science Japan, Vol. 50 (2001), pp. 651-656.

(4) Zhao, X., Xiao, P., Residual stresses in thermal barrier coatings measured by photoluminescence piezospectroscopy and indentation technique, Surface \& Coatings Technology, Vol. 201 (2006), pp.1124-1131.

(5) Kameda, J., Bloomer, T.E., Sugita, Y., Ito, A., Sakurai, S., High temperature environmental attack and mechanical degradation of coatings in gas turbine blades, Materials Science \& Engineering A234 (1997), pp.489-492.

(6) Arai, M., Ogata, T., Development of small fatigue testing machine for film materials, Transactions of the Japan Society of Mechanical Engineers, Vol. 68 (2002), pp.801-806.

(7) Arai, M., Development of small tensile tester for small materials - measurement of mechanical property under high-temperature environment -, Machine Science, Vol. 56 (2004), pp. 353-356.

(8) Arai, M., Development of in-situ SEM observation small high-temperature fatigue tester, Machine Science, Vol. 59 (2007), pp. 357-361.

(9) Thompson, J.A., Clyne, T.W., The effect of heat treatment on the stiffness of zirconia top coats in plasma-sprayed TBCs, Acta Materiallia, Vol. 49 (2001), pp.1565-1575. 